\section{WEB WATCH}

Lessons in histology

- http://eulep.anat.cam. ac.ukJ

Pathbase - a database of normal and transgenic mouse histology — is the kind of resource that developmental geneticists have been waiting for. Having engineered a specific mutant, mouse geneticists often lack the necessary expertise that is vital for the accurate analysis of mutant phenotypes. Well,

Pathbase is here to help.

The database can be searched - for example, by tissue or by the type of pathology. You can navigate around Pathbase using a simple menu, which also includes links to other useful sites and even information on pathology courses. By following a simple set of instructions, individuals who have completed a free registration can contribute images and pathology descriptions to Pathbase. There is also a bulletin board, called pathology forum, to which comments or questions can be submitted.

The project is curated by an international consortium of pathologists and veterinarians whose goal is also to develop standard histopathology and anatomy nomenclature. Although Pathbase is still being improved, it already contains useful data and in the future it might even include other organisms.

Magdalena Skipper

\section{Correcting the record}

- http://www.francisgalton. com/

If you're gasping in horror at the decision to devote this column to someone who pursued and defended eugenics, then this study of Sir Francis Galton in 11 PDF files could teach you a thing or two. Galton was a practical innovator, introducing the modern weather map, human fingerprinting, twin studies and coining the nature-nurture distinction. His statistical innovations laid the foundation for all social science. All in all, a true Victorian polymath.

Tanita Casci

\title{
GENETIC DISEASE
}

\section{Twin-track approach to fragile X}

About 8 years ago, the fragile $\mathrm{X}$ syndrome gene FMR1 was shown to encode an RNA-binding protein, but its physiological function has remained elusive. The most popular theory is that FMR1 regulates translation because it is associated with polysomal RNA. However, until now, there has been little information on the RNA targets that are bound by FMR1. Two papers in Cell report complementary studies aimed at finding such targets, and both converge on a small set of transcripts - encoded by genes involved in several aspects of neuronal function - that represent very strong candidates for regulation by FMR1.

The study by Victoria Brown, Peng Jin and colleagues involved two microarray experiments. In the first, mRNA isolated from mouse brain was compared with mRNA that had been immunoprecipitated with an FMR1 antibody, the aim being to find mRNA that was bound to FMR1. Of the $>25,000$ genes screened, 432 were identified that were enriched by immunoprecipitation. The second study compared polysomal RNA from fragile $\mathrm{X}$ with control human cell lines. The authors reasoned that if FMR1 regulates translation by binding to polysomal RNA, the absence of FMR1 in the fragile $\mathrm{X}$ cell lines should lead to differences in the abundance of specific polysomeassociated RNAs. In this experiment, $>35,000$ genes were compared, and 251 showed substantial differences in abundance between the polysomal RNA fractions of the fragile $\mathrm{X}$ and control cell lines. A partial comparison of the sets of genes revealed 14 that were identified in both experiments, and could therefore be targets for regulation by FMR1.

The second paper reports a biochemical approach to finding the optimal RNA target sequence for FMR1. After several rounds of selection from a pool of random RNA sequences, Jennifer Darnell et al.

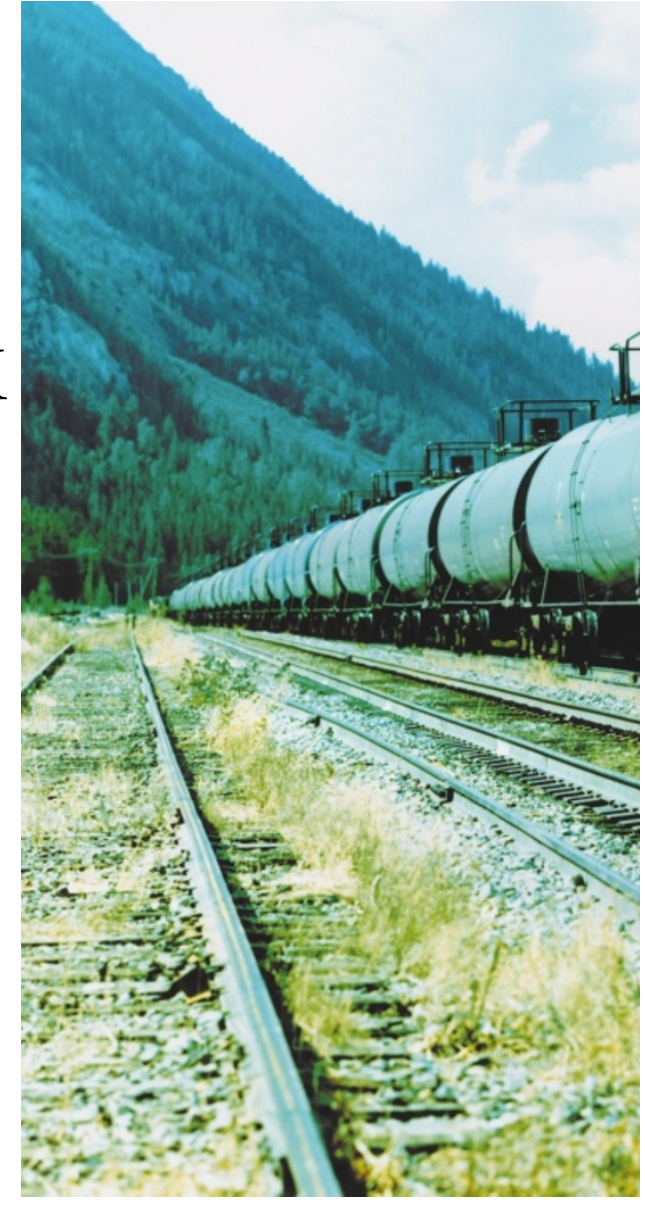

identified an RNA molecule that bound to FMR1 with high affinity. They then defined the minimal sequence required for binding, and concluded that FMR1 requires a specific RNA structure called a $G$ quartet, which is present in only a small percentage of transcripts.

\section{HUMAN GENETICS}

\section{C major variations}

Every year, malaria affects half a billion people and kills up to 3 million of them. For $\sim 10,000$ years, malaria has put the human genome under considerable selective pressure to evolve natural ways of resistance - the sickle cell haemoglobin ( $\mathrm{HbS})$ variant being a classic example. But other haemoglobin variants have been described and some, such as haemoglobin $\mathrm{C}(\mathrm{HbC})$, have been implicated in resistance to malaria. Until recently, the link has been tenuous, but Modiano and colleagues now provide conclusive evidence that, when homozygous, $\mathrm{HbC}$ confers substantial resistance to this devastating disease.

$\mathrm{HbC}$ is a common West African haemoglobin variant in which glutamic acid at position 6 has been mutated to lysine but, unlike the $\mathrm{HbS}$ mutation, this substitution does not affect the molecule's affinity for oxygen. Following inconclusive reports about the role of $\mathrm{HbC}$ in resistance to malaria, Modiano et al. re-examined the issue by looking at $\mathrm{HbC}$ frequency among 4,348 children in West African Burkina Faso. The authors found that $\mathrm{HbC}$ frequency was markedly reduced in 835 children who had been hospitalized with malaria; moreover, only one of these indivduals was homozygous for $\mathrm{HbC}$. Its frequency in the sick population indicates that, when heterozygous, $\mathrm{HbC}$ could account for a $29 \%$ reduction in the relative risk of clinical malaria and $93 \%$ when homozygous compared to $70 \%$ reduction among $\mathrm{HbS}$ carriers.

Given the very high level of protection that $\mathrm{HbC}$ bestows on homozygous individuals, and the lack of obvious adverse effects among $\mathrm{HbC}$ carriers, Modiano and colleagues suggest that the allele is likely to rise in frequency among Africans, and will perhaps even replace the $\mathrm{HbS}$ variant in Africa. But because its protective effects mainly manifest themselves in homozygotes, the spread of the allele is likely to be slow. It will also be useful to 


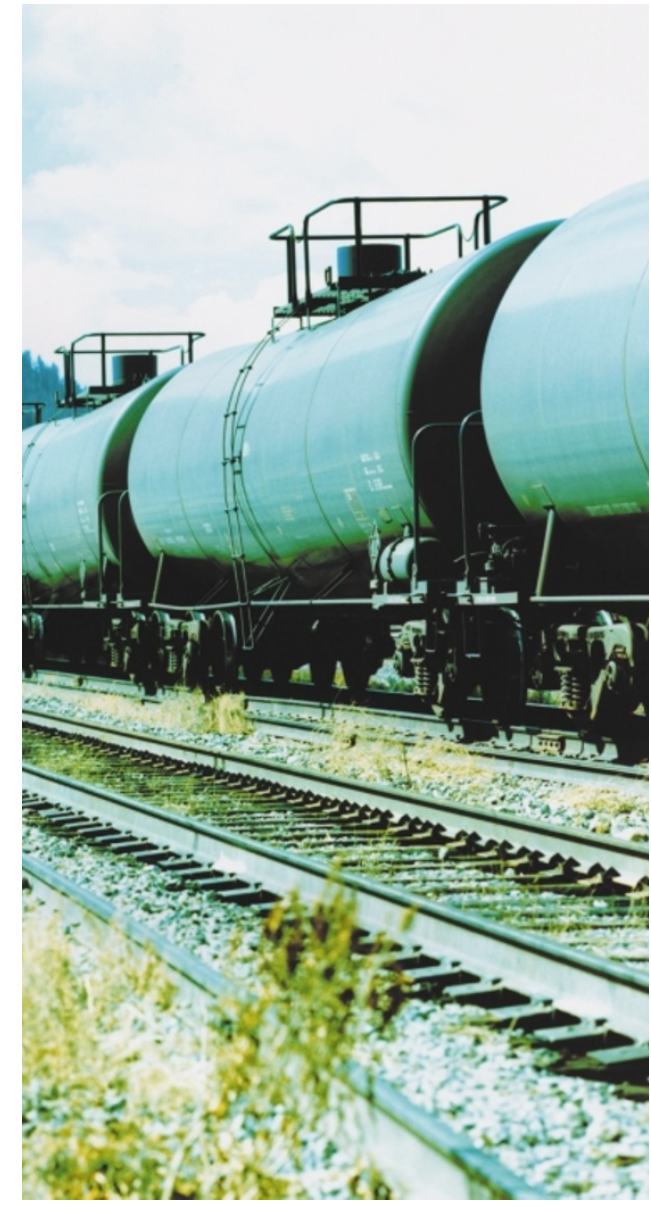

They tested 12 such transcripts for binding to FMR1, and found six that bound. So, there is more to find out about the requirements for FMR1 binding, but the presence of a $\mathrm{G}$ quartet is a good pointer.

Most satisfyingly, 8 of the 14 RNAs identified in the first study

understand the mechanism behind the protection afforded by $\mathrm{HbC}$ - this might provide some new insight into the biology of malaria and potentially lead to new treatments.

Magdalena Skipper

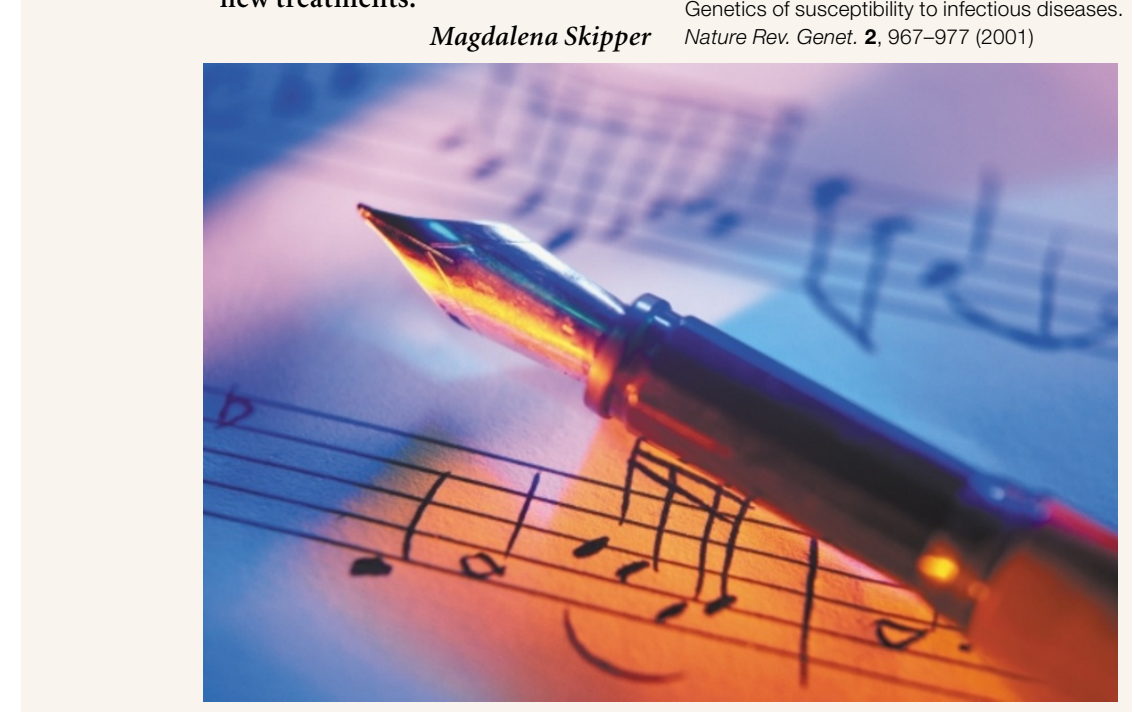

contained sequence that would be expected to form a G quartet, which reinforces the conclusions of both papers. Attention can now shift towards the genes that have been identified in these studies - and they are a tantalizing collection. Several genes are implicated in synaptic function or other aspects of neuronal biology. The study of these genes will help to pin down whether the key function of FMR1 is to regulate the translation of specific RNAs. Looking beyond fragile $\mathrm{X}$ syndrome, this twin-track approach is likely to be valuable for identifying the targets of other RNA-binding proteins.

Mark Patterson

\section{(2) References and links} ORIGINAL RESEARCH PAPERS Brown, V. et al. Microarray identification of FMRP-

associated brain mRNAs and altered mRNA translational profiles in fragile $X$ syndrome. Cell 107, 477-487 (2001) | Darnell, J. C. et al. Fragile X mental retardation protein targets $G$ quartet mRNAs important for neuronal function. Cell 107, 489-499 (2001)

FURTHER READING Chelly, J. \& Mandel, J.-L. Monogenic causes of $X$-linked mental retardation. Nature Rev. Genet. 2, 669-680 (2001)

\section{WEB SITES}

Stephen Warren's lab: http://www.hhmi.org/ research/investigators/warren.html Robert Darnell's lab: http://www.rockefeller.edu/ labheads/darnellb/newrsrch.htm

\section{(2) References and links} ORIGINAL RESEARCH PAPER Modiano, D. et al. Haemoglobin $\mathrm{C}$ protects against clinical Plasmodium falciparum malaria. Nature $\mathbf{4 1 4}$ 305-308 (2001)

FURTHER READING Hill, A. V. S. \& Cooke, G. Genetics of susceptibility to infectious diseases. Nature Rev. Genet. 2, 967-977 (2001)

H I G H L I G H TS

\section{IN BRIEF}

\section{CANCER GENETICS}

\section{$M L L$ translocations specify a distinct gene} expression profile that distinguishes a unique leukaemia.

Armstrong, S. A. et al. Nature Genet. 3 December 2001 (10.1038/ng765)

Some patients with acute lymphoblastic leukaemia (ALL) carry translocations in the mixed-lineage leukaemia $(M L L)$ gene and have a very poor prognosis. Because MLL regulates the expression of HOX genes, which function in haematopoiesis, the authors investigated whether $M L L$ translocations alter HOX gene expression to assess a role for these genes in the disease. Using microarray expression profiling, they surprisingly found that MLL patients have a highly uniform and distinct gene-expression profile, different from that of ALL or acute myelogenous leukaemia patients, indicating that MLL might be a distinct disease.

\section{EPIGENETICS}

Dnmt3L and the establishment of maternal genomic imprints.

Bourc'his, D. et al. Science, 22 November 2001 (10.1126/science.1065848)

Bourc'his et al. knocked out the DNA methyltransferase $D n m t 3 L$ in mice to investigate its role in establishing and maintaining genomic imprints. They found that heterozygous progeny from $D n m t 3^{-/-}$females die before mid-gestation with developmental and placental defects. Furthermore, Dnmt3L $\mathrm{L}^{+/-}$ embryos derived from homozygous mutant oocytes lack maternal imprints, causing genes that are normally expressed from only the paternal allele to be biallelically expressed. Genome-wide methylation levels were otherwise normal, indicating that $D n m t 3 L$ is the first known gene to be essential for the de novo methylation of single-copy sequence. In addition, its sequence indicates that it is more likely to act as a regulator of methylation at imprinted loci than as a DNA methyltransferase.

\section{POPULATION GENETICS}

Female sticklebacks count alleles in a strategy of sexual selection explaining $\mathrm{MHC}$ polymorphism.

Reusch, T. B. H. et al. Nature 414, 300-302 (2001)

Many theories have been proposed to explain the polymorphism of major histocompatibility complex (MHC) genes, which are important in vertebrate immunity. This report states that, contrary to previous studies in human and mice, which indicated that females select mates with an MHC complement most dissimilar to their own to avoid the consequences of inbreeding, female sticklebacks prefer males with the largest number of different MHC loci. Maximizing the number of MHC alleles in offspring presumably increases their fitness by boosting resistance to parasites. The authors suggest that two non-exclusive strategies exist to maintain MHC polymorphism in vertebrates: inbreeding avoidance and parasite resistance. 